\title{
A Novel Alternative Algorithm for Solving Linear Integer Programming Problems with Four Variables
}

\author{
Kadriye Şimşek Alan ${ }^{1 *}$ \\ 1* Yildiz Technical University, Faculty of Chemistry and Metallurgy, Department of Mathematical Engineering, Istanbul, Turkey (ORCID: 0000-0001-6751-8013), \\ ksimsek@yildiz.edu.tr
}

(International Symposium on Multidisciplinary Studies and Innovative Technologies (ISMSIT) 2021 - 21-23 October 2021)

(DOI: $10.31590 /$ ejosat.1020212)

ATIF/REFERENCE: Şimşek Alan, K. (2021). A Novel Alternative Algorithm for Solving Linear Integer Programming Problems with Four Variables. European Journal of Science and Technology, (29), 81-86.

\begin{abstract}
In this paper, new iterative method is proposed based on parametrization for solving Integer Linear Programming (ILP) problems with four variables and an algorithm is provided. Our method, which is better than the cutting plane method and branch and bound methods in solving ILP problems with four variables, can be easily applied regardless of the number of constraints. In addition, in our method, all alternative solutions are found and presented to the decision maker. A numerical example is solved by applying the proposed method.
\end{abstract}

Keywords: Integer linear programming, Linear Diophantine equations, Integer programming problems, Optimal solution.

\section{Dört Değişkenli Doğrusal Tamsayılı Programlama Problemlerinin Çözümü İçin Yeni Bir Alternatif Algoritma}

Öz

Bu çalışmada, dört değişkenli Tamsayılı Doğrusal Programlama problemlerinin çözümü için parametrizasyona dayanan yeni iterativ bir yöntem önerilmiş ve bir algoritma sunulmuştur. Dört değişkenli DTP problemlerinin çözümünde kesme düzlemi yöntemi ve dal-sınır yöntemlerinden daha iyi olan yöntemimiz, kısıtlama sayısından bağımsız olarak kolaylıkla uygulanabilmektedir. Ayrıca yöntemimizde tüm alternatif çözümler bulunur ve karar vericiye sunulur. Önerilen yöntem uygulanarak sayısal bir örnek çözülmüştür.

Anahtar Kelimeler: Tamsayılı doğrusal programlama, Doğrusal Diophantine denklemleri, Tamsayılı programlama problemleri, Optimal çözüm. 


\section{Introduction}

Linear programming (LP) is a sub-field of operations research in which the objective function and its constraints are written as linear functions. Certain effective algorithms, such as the simplex algorithm, are used to solve linear programming problems. In LP problems, the variables are usually non-integer values, but the quantities to be modeled are usually essentially integers. Linear programming in which variables are only allowed to be integers in this way is called integer programming (IP). Integer programming (IP), also known as discrete optimization or combinatorial optimization, helps in developing decision strategies in a wide range of fields, from engineering to economics or from management to the military field. In these features, it is characterized as a sub-domain of mathematical programming that is the most popular and widely studied. Many researchers have also conducted studies in this area.

One of these researchers, Gomory presented a cutting plane algorithm to otain the optimal solution for IP problems (Gomory, 1958); others solve the ILP using enumerative approaches, the most popular of them is branch-and-bound (Chen et.al., 2011). Important studies in this field (Joseph, 1995; Pandian and Jayalakshmi, 2012; Tsai et al.,2008.; Mohamad and Said, 2013; Genova and Guliashki, 2011; Hossain and Hasan, 2013; Shinto and Susmaha, 2013) can be cited. Another important study in this area was done by Bertsimas et al.. Bertsimas et. al suggested a novel algorithm for solving IP problems that are based on algebraic geometry (Bertsimas, 2000) . Tantawy introduced a novel procedure for solving ILP problems with an objective function of linear functions and with a constraint set of linear inequalities, which are based on the conjugate gradient projection method (Tantawy, 2014). Dang and Ye developed an alternative method, called a fixed point iterative method, for integer programming by constructing an increasing mapping that satisfies certain properties (Dang and Ye, 2015). Pedrosa presented an evolutionary algorithm for solving püre ILP problems. In this algorithm, all the variables of the problem are fixed by the evolutionary system (Pedrosa, 2002). In another study (Şimşek Alan et al., 2019), an alternative iterative method based on parameterization was developed to solve pure ILP problems with two variables. The method proposed in this study is easy to implement, efficient, but can only be used to solve pure ILP problems with two variables. Simsek Alan developed the method presented by Simsek Alan et al. (2019) for solving ILP problems with three variables (Simsek Alan, 2020). If this method given by Simsek Alan is developed for solving ILP problems with four variables, the obtained method becomes the basis for solving ILP problems with $\mathrm{n}$ variables. For this reason, the development of this method for solving ILP problems with four variables is of critical importance, both theoretically and practically.

Therefore, in this study, a new iterative method based on parameterization is developed for solving ILP problems with four variables. In addition, an easy-to-apply and useful algorithm for the solution of ILP problems with four variables is given,
This paper is organized as follows: Section 2 includes some necessary information. In Section 3 is given the proposed approach. Sections 4 and 5 is presented our numerical example and conclusions, respectively.

\section{Preliminaries}

Definition 1: The mathematical formulation of an ILP problem is described below.

$$
P_{1}:\left\{\begin{array}{c}
\operatorname{Max}(\operatorname{Min}) \sum_{j=1}^{n} c_{j} x_{j} \\
\sum_{\substack{j=1 \\
x_{j}} a_{i j} x_{j} \leq b_{i},} \text { and integer, } \quad(\mathrm{i}=1,2, \ldots \mathrm{m})
\end{array}\right.
$$

(Chen, 2011).

Definition 2: Consider the objective hyperplane

$\sum c_{j} x_{j}=z$,

Where each $c_{j} \in Z$, which is a linear Diophantine equation in integers. Let $d=\operatorname{gdc}\left(c_{j}, c_{j} \neq 0, j=1,2, \ldots, n\right)$. It has an integer solution if and only if $d \mid z$. Additionally, if a linear Diophantine equation has an integer solution, there will be infinitely many solutions for this equation (Schrijver, 1986)

Theorem 1: $\left(x_{1}, x_{2}, \ldots, x_{n}, z\right)$ is a solution of the problem if and only if $\left(x_{1}, x_{2}, \ldots, x_{n}\right)$ satisfies all constraints of $P_{1}$ (Schrijver, 1986).

\section{Results and Discussion}

\subsection{The Proposed Algorithm for Solving the Integer Linear Programming Problem with Four Variables}

The proposed algorithm to an ILP problem with four variables consists of these steps:

Step 0: Load LP problem $\mathrm{P}_{1 .}$.

Step 1: Solve the relaxed LP problem $\mathrm{P}_{1}$ to obtain the optimal solution $x^{*}$.

Step 2: If $x^{*} \in Z^{n}$, then this is the desired optimal solution $x^{*}$. Stop. If not, go to step 3 .

Step 3: Set $c^{T} x=z^{*}$.

Step 4: Assign the parametric variables $y_{1}, y_{2}, y_{3}, y_{4}$ to $x_{1}, x_{2}, x_{3}, x_{4}$ respectively, and then replace them with $c^{T} x=$ $z^{*}$. Then find an arbitrary parametric variable from the linear Diophantine equation $c^{T} x=z^{*}$.

Step 5: Substitute these parametric variables into $x_{1}, x_{2}, x_{3}, x_{4}$ in the inequality system.

Step 6: Find the domain interval $a_{1} \leq y_{i} \leq b_{1}$ for an arbitrary parametric variable $y_{i}$ from $\left\{y_{1}, y_{2}, y_{3}, y_{4}\right\}$.

Step 7: Set $a=\left\lfloor a_{1}\right\rfloor$ (Where $\left\lfloor a_{1}\right\rfloor$ is the greatest integer less than or equal to $a_{1}$ ) and assign a to $y_{i}$.

Step 8: Put a in $y_{i}$ in the system of inequalities.

Step 9: Draw the system of inequalities.

Step 10: Check if there are integers points belonging to the twodimensional region. If there are integer points belonging to the 
two-dimensional region go to step 11 . Otherwise, put b into $y_{i}$ and go to Step 8.

Step 11: If there are integer points belonging to this region obtained, the value of the parametric variable is calculated using these integer points. If the fourth parametric variable is an integer, the desired optimal solution $x^{*}$ is found. If the fourth parametric variable is not an integer, or there are no integer points of the twodimensional region, then in the maximization problem (minimization problem), $z^{*}$ is replaced by $\left\lfloor z_{L P}\right\rfloor-1 \quad\left(\left\lfloor z_{L P}\right\rfloor+1\right.$ ) and go to step 3 .

\subsection{Numerical Experiment}

Example 1. Consider the following ILP problem.

Step 0:

$P_{1} \operatorname{Max} 9 x_{1}+5 x_{2}+6 x_{3}+4 x_{4}$

Subject to

$$
\begin{gathered}
6 x_{1}+3 x_{2}+5 x_{3}+2 x_{4} \leq 10 \\
x_{3}+x_{4} \leq 1 \\
-x_{1}+x_{3} \leq 0 \\
-x_{2}+x_{4} \leq 0
\end{gathered}
$$

$x_{1} \geq 0, x_{2} \geq 0, x_{3} \geq 0, x_{4} \geq 0$, and integers.

Step 1: If we solve the relaxed LP problem, $P_{1}:\left(x_{1}, x_{2}, x_{3}, x_{4}\right)=$ $(0,2.66,0,1)$ and optimal value $z=17.33$ are found.

Step 2: There exists no integer solution; go to Step 3.

Step 3: Set $9 x_{1}+5 x_{2}+6 x_{3}+4 x_{4}=17$.

Step 4: If you set $x_{1}=y_{1}, x_{2}=y_{2}, x_{3}=y_{3}$, and $x_{4}=y_{4}$, you get the Diophantine Equation $9 y_{1}+5 y_{2}+6 y_{3}+4 y_{4}=17$. From this Diophantine Equation $y_{2}=\frac{17-\left(9 y_{1}+6 y_{3}+4 y_{4}\right)}{5}$ is obtained.

Step 5: Substituting $y_{1}, \frac{17-\left(9 y_{1}+6 y_{3}+4 y_{4}\right)}{5}, y_{3}$ and $y_{4}$ for $x_{1}$, $x_{2}, x_{3}$ and $x_{4}$ in the constraints, the inequality system

$$
\begin{gathered}
-3 y_{1}-7 y_{3}+2 y_{4} \geq 1 \\
y_{3}+y_{4} \leq 1 \\
-y_{1}+y_{3} \leq 0 \\
9 y_{1}+6 y_{3}+9 y_{4} \leq 17
\end{gathered}
$$

$$
\text { is obtained. }
$$

Step 6: From this system of inequalities, the domain interval $0 \leq$ $y_{4} \leq 1$ for the parameter $y_{4}$ is obtained.

Step 7: Set $y_{4}=0$.

Step 8: If 0 is substituted into $y_{4}$ in the inequality system given in (3.1), then the following inequality system is obtained.

$$
\begin{gathered}
-3 y_{1}-7 y_{3} \geq 1 \\
y_{3} \leq 1 \\
-y_{1}+y_{3} \leq 0 \\
9 y_{1}+6 y_{3} \leq 17
\end{gathered}
$$

Step 9: Draw the two dimensional region of the inequality system given in (3.2).

Step 10: Since there are no integer points in the two-dimensional region, set $y_{4}=1$ and go to step 8 .

Step 8: If 1 is substituted into $y_{4}$ in the inequality system given in (3.2), then the following inequality system is obtained.

$$
\begin{gathered}
3 y_{1}+7 y_{3} \leq 1 \\
y_{3} \leq 1 \\
-y_{1}+y_{3} \leq 0 \\
9 y_{1}+6 y_{3} \leq 8
\end{gathered}
$$

Step 9: Draw the two dimensional region of the inequality system given in (3.3).

Step 10: There is a point $\left(y_{1}, y_{3}\right)=(0,0)$ in the two-dimensional region of the inequality system given by (3.3).

Step 11: In the equation $y_{2}=\frac{17-\left(9 y_{1}+6 y_{3}+4 y_{4}\right)}{5}$, if 0 is substituted into $y_{1}, 0$ into $y_{3}$, and 1 into $y_{4}, y_{2}=\frac{13}{5}$ is obtained. Since $\frac{13}{5} \notin$ $Z^{+}$, the optimal value $z^{*}$ cannot be 17 . For this reason, the optimal value $z^{*}$ is taken as 16 by decreasing it by one unit and and If you go to step 3 and apply the steps of the suggested algorithms, for the optimal value 15 , The Diophantine equation

$9 y_{1}+5 y_{2}+6 y_{3}+4 y_{4}=15 \quad$ is obtained. From this Diophantine Equation, $y_{2}=\frac{15-\left(9 y_{1}+6 y_{3}+4 y_{4}\right)}{5}$ is obtained. Substituting $y_{1}, \frac{15-\left(9 y_{1}+6 y_{3}+4 y_{4}\right)}{5}, y_{3}$ and $y_{4}$ for $x_{1}, x_{2}$, $x_{3}$ and $x_{4}$ in the constraints, then the inequality system

$$
\begin{gathered}
3 y_{1}+7 y_{3}-2 y_{4} \leq 5 \\
y_{3}+y_{4} \leq 1 \\
-y_{1}+y_{3} \leq 0 \\
9 y_{1}+6 y_{3}+9 y_{4} \leq 15
\end{gathered}
$$

is obtained. From this system of inequalities, the domain interval $0 \leq y_{4} \leq 1$ for the parameter $y_{4}$ is obtained. According to the steps of the algorithm, if this inequality system is solved, the integer point $\left(y_{1}, y_{3}, y_{4}\right)=(0,0,0)$ is found. In the equation

$$
y_{2}=\frac{15-\left(9 y_{1}+6 y_{3}+4 y_{4}\right)}{5} \text {, if } 0 \text { is substituted into } y_{1}, 0 \text { into } y_{3} \text {, }
$$
and 0 into $y_{4}, y_{2}=3$ is obtained. Since $3 \in Z^{+}$, the point $(0,3,0,0)$ is an integer solution for the optimal value 15 . In addition, to investigate whether there is an integer solution for $\mathrm{y}=1$, if you go to step 8 and apply the steps given in the algorithm, it is seen that there is no optimal solution to the problem except $(0,3,0,0)$. The results of Example 1 are summarized in Table 1. 
Table 1. Summarized results of Example 4.1

\begin{tabular}{|c|c|c|c|c|c|c|c|}
\hline $\begin{array}{l}\text { Optimal } \\
\text { value } \\
Z^{*}\end{array}$ & $y_{2}$ & Inequality systems & $y_{4}$ & $\begin{array}{l}\text { Inequalities with respect } \\
\text { to the point }\left(y_{1}, y_{3}\right)\end{array}$ & $\begin{array}{l}\text { Is there at least } \\
\text { one integer point } \\
\left(y_{1}, y_{3}\right) \text { satisfyin } \\
\mathrm{g} \text { the inequality? }\end{array}$ & $\begin{array}{l}\text { Is } y_{2} \\
\text { an integer? }\end{array}$ & $\begin{array}{l}\text { Is }\left(y_{1}, y_{2}, y_{3}, y_{4}\right) \\
\text { an integer solution? }\end{array}$ \\
\hline \multirow[b]{2}{*}{17} & \multirow[b]{2}{*}{$\frac{17-\left(9 y_{1}+6 y_{3}+4 y_{4}\right)}{5}$} & \multirow{2}{*}{$\begin{array}{c}-3 y_{1}-7 y_{3}+2 y_{4} \geq 1 \\
y_{3}+y_{4} \leq 1 \\
-y_{1}+y_{3} \leq 0 \\
9 y_{1}+6 y_{3}+9 y_{4} \leq 17\end{array}$} & 0 & $\begin{array}{c}-3 y_{1}-7 y_{3} \geq 1 \\
y_{3} \leq 1 \\
-y_{1}+y_{3} \leq 0 \\
9 y_{1}+6 y_{3} \leq 17\end{array}$ & No & No & No \\
\hline & & & 1 & $\begin{array}{c}3 y_{1}+7 y_{3} \leq 1 \\
y_{3} \leq 0 \\
-y_{1}+y_{3} \leq 0 \\
9 y_{1}+6 y_{3} \leq 8\end{array}$ & $(0,0)$ & $\begin{array}{l}\text { No } \\
\left(\frac{13}{5}\right)\end{array}$ & No \\
\hline \multirow{2}{*}{16} & \multirow[b]{2}{*}{$\frac{16-\left(9 y_{1}+6 y_{3}+4 y_{4}\right)}{5}$} & \multirow{2}{*}{$\begin{array}{c}3 y_{1}+7 y_{3}-2 y_{4} \leq 2 \\
y_{3}+y_{4} \leq 1 \\
-y_{1}+y_{3} \leq 0 \\
9 y_{1}+6 y_{3}+9 y_{4} \leq 16\end{array}$} & 0 & $\begin{array}{c}3 y_{1}+7 y_{3} \leq 4 \\
y_{3} \leq 1 \\
-y_{1}+y_{3} \leq 0 \\
9 y_{1}+6 y_{3} \leq 16\end{array}$ & $(0,0)$ & $\begin{array}{l}\text { No } \\
\left(\frac{16}{5}\right)\end{array}$ & No \\
\hline & & & 1 & $\begin{array}{c}3 y_{1}+7 y_{3} \leq 0 \\
y_{3} \leq 0 \\
-y_{1}+y_{3} \leq 0 \\
9 y_{1}+6 y_{3} \leq 7\end{array}$ & $(0,0)$ & $\begin{array}{l}\text { No } \\
\left(\frac{12}{5}\right)\end{array}$ & No \\
\hline \multirow{2}{*}{15} & \multirow{2}{*}{$\frac{15-\left(9 y_{1}+6 y_{3}+4 y_{4}\right)}{5}$} & \multirow{2}{*}{$\begin{array}{c}3 y_{1}+7 y_{3}-2 y_{4} \leq 5 \\
y_{3}+y_{4} \leq 1 \\
-y_{1}+y_{3} \leq 0 \\
9 y_{1}+6 y_{3}+9 y_{4} \leq 15\end{array}$} & 0 & $\begin{array}{c}3 y_{1}+7 y_{3} \leq 5 \\
y_{3} \leq 1 \\
-y_{1}+y_{3} \leq 0 \\
9 y_{1}+6 y_{3} \leq 15\end{array}$ & $(0,0)$ & $\begin{array}{c}\text { Yes } \\
3\end{array}$ & $\begin{array}{c}(\mathbf{0}, \mathbf{3}, \mathbf{0}, \mathbf{0}) \\
\text { ( Integer Solution) }\end{array}$ \\
\hline & & & 1 & $\begin{array}{c}3 y_{1}+7 y_{3} \leq 7 \\
y_{3} \leq 0 \\
-y_{1}+y_{3} \leq 0 \\
9 y_{1}+6 y_{3} \leq 6\end{array}$ & $(0,0)$ & $\begin{array}{l}\text { No } \\
\left(\frac{11}{5}\right)\end{array}$ & No \\
\hline
\end{tabular}




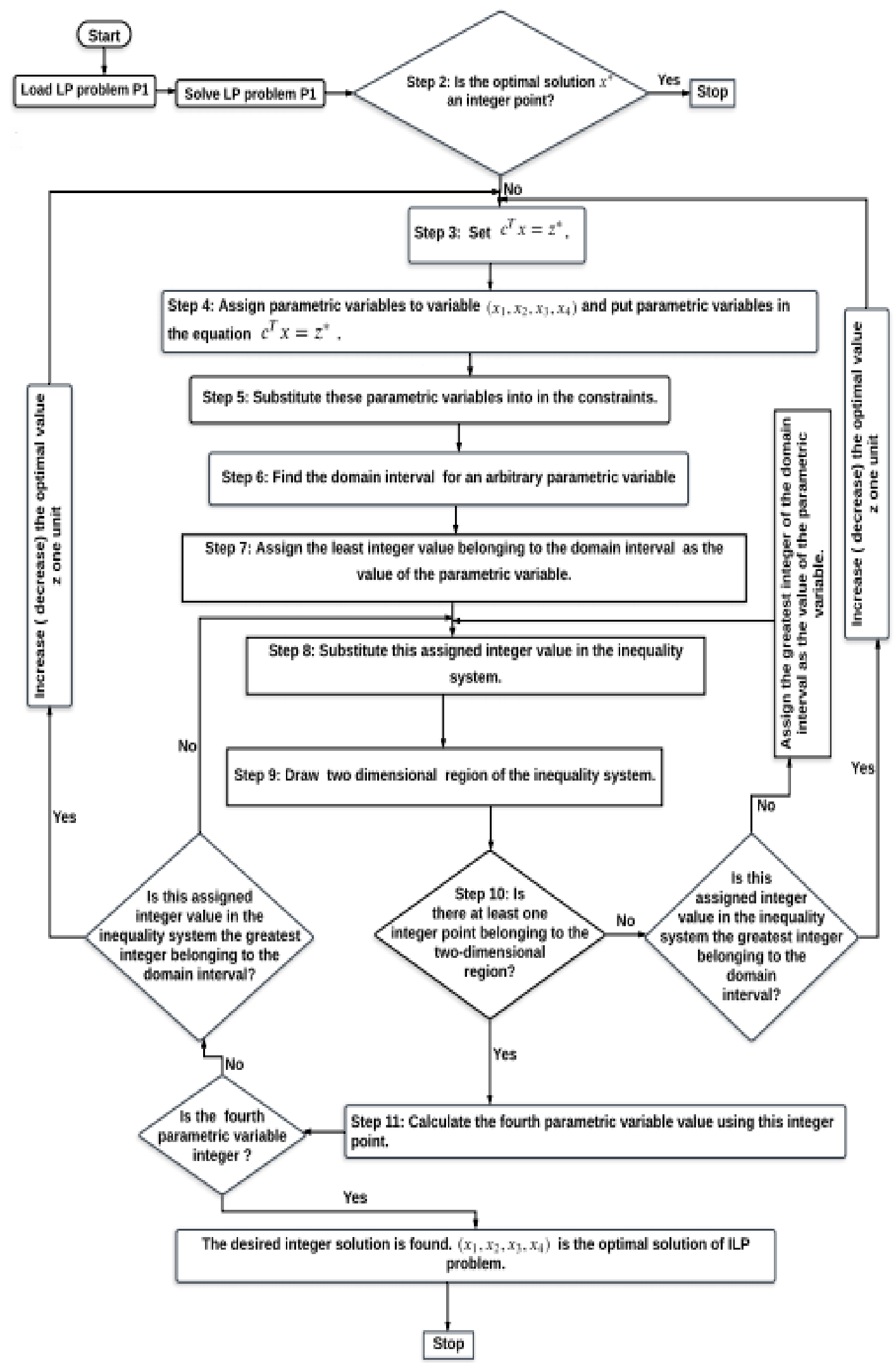

Fig. 1 The flow chart of the proposed solution Method 


\section{Conclusions}

This study proposes, using basic algebraic geometry information, a method for solving ILP problems with four variables and presents an easily applicable alternative algorithm. Many methods used for solving ILP problems have some difficulties in terms of calculation and process time. Our method is free of such difficulties and has many advantages compared to other methods that are used for solving ILP problems. These advantages are as follows:

1. Integer programming problems are complex problems in terms of calculation and process time. The approach developed in the present study has no complexity and, thus, requires a very short process time.

2. Since only a small portion of the appropriate solution area is addressed in the branch-bound technique, many possible solutions might be ignored. However, no optimal solution is ignored with our method because all appropriate solutions are investigated.

3. As the number of constraints increases in the branchbound and the cutting plane method, a serious load of process emerges. In our method, by contrast, the optimal solution is easily accessible independently of the number of constraints.

4. The graphical method can only be used for the solution of ILP problems with two variables. However, the proposed method can be used for the solution of ILP problems with four problems.

\section{Acknowledge}

This work was supported by Yildiz Technical University

Scientific Research Projects Coordination Unit. Project Number:

FBA-2021-4032.

\section{References}

Bertsimas, D., Perakis, G., Tayur, S. (2000). A new algebraic geometry algorithm for integer programming. Management Science, 46(7), 999-1008.

Chen, D. S., Batson, R. G., Dang, Y. (2015). Applied integer programming: modeling and solution, pp. 3-4. John Wiley \& Sons, New Jersey, 2011.

Dang, C., Y. Ye. (2015). A fixedpoint iterative approach to integer programming and its distributed computation. - Fixed Point Theory and Applications. 182, 1-15.

Genova, K., Guliashki, V. (2011). Linear integer programming methods and approaches-a survey. - Journal of Cybernetics and Information Technologies, 11(1), 1-23.

Gomory, Ralph E. (1958) Outline of an Algorithm for Integer Solutions to Linear Programs. Bull. Amer. Math. Soc. 64(5): 275-278.

Hossain, M. I., Hasan, M. B. (2013). A Decomposition Technique For Solving Integer Programming Problems. GANIT: Journal of Bangladesh Mathematical Society, 33, 1-11.

Joseph, A. (1995). Parametric formulation of the general integer linear programming problem. - Computers \& operations research, 22(3), 883-892.

Mohamad, N. H., \& Said, F. (2013). Integer linear programming approach to scheduling toll booth collectors problem. Indian Journal of Science and Technology, 6(5), 4416-4421.
Pandian, P., \& Jayalakshmi, M. (2012). A New Approach for solving a Class of Pure Integer Linear Programming Problems. Journal of Advanced Engineering Technology, 3, 248-251.

Pedroso, J. P. (2002). An evolutionary solver for pure integer linear programming. International Transactions in Operational Research, 9(3), 337-352.

Schrijver, A. (1986). "Theory of Linear and Integer Programming", John Wiley \& Sons Ltd.

Shinto, K. G., \& Sushama, C.M. (2013). An Algorithm for Solving Integer Linear Programming Problems. International Journal of Research in Engineering and Technology, 37-47.

Simsek Alan, K., Albayrak, I., M., Sivri, M., Guler, C. (2019). An Alternative Algorithm for Solving Linear Programming Problems Having Two Variables, - International Journal of Applied Information Systems. 12 (25), 6-9.

Simsek Alan, K. (2020). An Novel Algorithm for Solving Linear Programming Problems Having Three Variables. J. Cyber. and Inform. Technologies 20 (4), 27-35.

Tantawy, S. F. (2014). A new procedure for solving integer linear programming problems. - Arabian Journal for Science and Engineering. 39 (6), 5265-5269.

Tsai, J. F., Lin, M. H., Hu, Y. C. (2008). Finding multiple solutions to general integer linear programs. - European Journal of Operational Research, 184(2), 802-809. 